\title{
Технологии в уголовном законодательстве России: проблемы и перспективы
}

В. Н. НЕКРАСОВ - доцент кафедры уголовного права и криминологии юридического факультета ВИПЭ ФСИН России, кандидат юридических наук

Реферат

В статье предпринимается попытка рассмотреть вопросы влияния такого вида результатов инновационной деятельности, как технологии, на отечественный уголовный закон и сделать вывод о готовности ныне действующего закона к появляющимися новшествам. В работе изучены технологические инновации как орудия и средства преступления. Кроме того, исследованы проблемные вопросы конструирования Уголовного кодекса Российской Федерации с использованием новых понятий, связанных с развитием инновационной деятельности. Автор делает вывод о том, что в настоящее время назрела необходимость объединения норм в области преступлений, посягающих на инновационную деятельность, в отдельную группу.

К лючев ы е слов а: уголовный закон; инновационная деятельность; преступление.

12.00.08 - Уголовное право и криминология; уголовно-исполнительное право

\section{Technologies in the criminal legislation of Russia: problems and prospects}

V. N. NEKRASOV - Associate Professor of the Department of Criminal Law and Criminology of the Law Faculty of the Vologda Institute of Law and Economics of the Federal Penal Service of Russia, PhD. in Law

Abstract

The article attempts to consider the impact of this type of innovation results, such as technology, on the domestic criminal law and conclude that the current law is ready for emerging innovations. In the work technological innovations as tools and means of crime are studied. In addition the author investigated the problematic issues of constructing the Criminal Code of the Russian Federation using new concepts related to the development of innovative activity. The author concludes that at present the need has arisen for combining the norms in the field of crimes encroaching on innovative activity into a separate group of norms.

Key word s: criminal law; innovative activity; crime.

12.00.08 - Criminal law and criminology; penal law 
В результате развития инновационных технологий при их несомненных благах в сфере экономики, образования и культуры все острее встает проблема противодействия преступности в данной сфере. Сегодня никого не удивишь преступлениями, совершенными с использованием электронных средств платежа, компьютерных программ и т. п. Более того, стремительное развитие робототехники и искусственного интеллекта приводит к тому, что в мире уже появляются идеи признания роботов в качестве самостоятельных субъектов права, в том числе уголовного [6]. Вместе с тем для законодателя проблема включения технологий в уголовное законодательство, с одной стороны, не нова, с другой - обладает рядом специфических особенностей в связи с их бурным развитием в последнее время. В данной статье делается попытка рассмотреть вопросы влияния такого вида результатов инновационной деятельности, как технологии, на отечественный уголовный закон и разобраться, готов ли законодатель к их появлению.

Начать следует с того, что в действующем УК РФ законодатель ни разу не использует применительно к техническим нововведениям единого обобщающего понятия, позволяющего в совокупности охарактеризовать различные элементы.

Технические нововведения в УК РФ рассматриваются как орудия или средства совершения преступления. Так, например, средством, используемым для совершения преступления, предусмотренного ст. 159.3, являются электронные средства платежа. Под электронными средствами платежа, исходя из ст. 3 Федерального закона от 27.06.2011 № 161-Ф3 «О национальной платежной системе», следует понимать средство и (или) способ, позволяющие клиенту оператора по переводу денежных средств составлять, удостоверять и передавать распоряжения в целях осуществления перевода денежных средств в рамках применяемых форм безналичных расчетов с использованием информационно-коммуникационных технологий, электронных носителей информации, в том числе платежных карт, а также иных технических устройств. Иными словами, особенность анализируемого состава преступления заключается в том, что преступление совершается благодаря такой технологии, как электронные средства платежа.

В разные исторические периоды содержание термина «техника» рассматривалось по-разному:
- на этапе использования ручных орудий труда, когда важным было умение человека работать ими, под техникой понимались искусство и мастерство;

- в условиях ремесленного производства, когда наряду с мастерством возросла и роль орудий труда в производственном процессе, под техникой стали понимать не только искусство работника, но и средства его труда (английское слово «technolodgy» означает и технику, и технологию);

- с переходом в начале XIX в. к крупному машинному производству, когда индивидуальное мастерство рабочего оказалось не столь важным, под техникой стали понимать материальные средства труда;

- сегодня, когда техника внедрилась в человеческую деятельность, под техникой понимаются искусственно созданные средства человеческой деятельности, овеществленное знание [9, с. 10].

Новые виды техники нередко называют высокими технологиями, которые стали обладать рядом специфических характеристик в отличие от технологий предыдущих периодов. Как верно отмечает Е. А. Жукова, принципиальными отличиями высоких технологий от других технологий являются:

- усиление в принципиальной степени темпов и сил воздействия хай-тек, вызывающих обратные связи, что приводит к быстрым и необратимым системным изменениям социокультурной действительности;

- стремление исключить непосредственное участие человека из сферы постановки задач;

- механизмы воздействия хай-тек на социокультурную действительность и человека определяются их информационной природой: функции высоких технологий перестраивают формы культуры и формируют различные модели поведения человека [4, с. 9].

Иными словами, под воздействием инновационной деятельности и такой ее составляющей, как развитие технологий, происходит трансформация общественных отношений. А раз общественные отношения претерпевают определенные изменения, следовательно, происходят модификации и в объекте преступления, под которым традиционно понимаются общественные отношения в определенных сферах.

Сегодня все большее число философов отмечают тенденцию, согласно которой развитие инновационной деятельности изменяет последовательность отношений «человек - техника». Так, например, члены Римского клуба видят угрозу действительности 
не в развитии техники как таковой, а в изменениях личности, изменениях системы ценностей, которые происходят под влиянием техники [2, с. 171]. По мнению А. А. Дурова, В. А. Починской и А. Р. Шариповой, «расстояние между человеком и техникой стремительно сокращается. По мере его сокращения отчетливо обозначаются две тенденции - технизация человека и гуманизация машины. Если эти тенденции «разойдутся» друг с другом, то картины из фантастических романов перестанут быть фантастическими: роботу, более человечному, чем человек, и человеку-программе будет тесно на страницах sci-fi» [3, c. 9]. Далее указанные авторы пытаются ответить на вопрос, можно ли отказать технике в субъектности, если она теснит и окружает человека, переходит границы и вызывает зависимость. Он настолько отвлеченный, что ответ может быть и положительным, и отрицательным. Положительный ответ основывается на многовековой истории человека разумного - единственного существа, способного к познанию и преобразованию мира, творца религии, философии, науки и техники. Отрицательный ответ связан с возможностью бунта творения против творца. По выражению М. Н. Эпштейна, если человек создан по образу и подобию Бога и наделен свободой воли, то он может передавать эту "эстафету" своим творениям» [3, с. 9].

Конечно, до признания техники, в частности роботов, оснащенных системами искусственного интеллекта высокого уровня, еще далеко, однако этот вопрос все острее встает перед законодателем, и решать его придется. В этой связи автор придерживается позиции, согласно которой в преступлениях, связанных с результатами инновационной деятельности, подлежит установлению вина человека. Здесь нельзя не согласиться с В. Цветовым, который отмечал, что «чем выше и ярче высоты научно-технического прогресса, тем важнее становится человек, без которого роботы, ЭВМ, станки с числовым программным управлением - не более чем замысловатая груда металла» [10, с. 37].

Вместе с тем в отечественном уголовном законе уже сегодня имеют место ранее не встречавшиеся дефиниции, позволяющие судить о новых возможностях техники, которые только стимулируют дискуссию о правом положении технологий как в уголовном праве, так и в законодательстве в целом. В частности, при конструировании ст. 274.1 УК РФ законодатель использовал при характеристике нарушения правил эксплуатации средств хранения, обработки или передачи охраняемой компьютерной информации словосочетание «автоматизированные системы управления». Традиционно под последними понимаются комплексы аппаратных и программных средств, а также персонала, предназначенные для управления различными процессами в рамках технологического процесса, производства, предприятия. Автоматизированные системы управления применяются в различных отраслях промышленности, энергетике, транспорте и т. п. [1]. Примечательно, что в толковом словаре русского языка слово «автоматизм» определено следующим образом: «механичность, непроизвольность действий, движений». В свою очередь, в том же словаре слово «система» понимается как «определенный порядок в расположении и связи действий», а слово «управление» как «совокупность приборов, приспособлений, устройств, посредством которых управляется ход машины, механизма» [7, с. 17, 719, 836]. Исходя из формального толкования, получается, что автоматизированная система управления представляет собой механический, в ряде случаев непроизвольный порядок расположения действий по управлению техническими приборами. В этой связи обращают на себя внимание два момента. В частности, толкование слова «автоматизированный» предполагает в том числе и непроизвольность, иными словами неконтролируемость действий. Для сферы права, особенно уголовного, это крайне опасная конструкция. В этой связи включение анализируемого понятия в текст уголовного закона представляется преждевременным.

Обращает на себя внимание и то, что автоматизированная система управления, как отмечалось ранее, предполагает управление техническими средствами, а не человеком. Сегодня же происходит совсем по-другому. В первую очередь автоматизированные системы управления предназначены для управления процессами, но не только. В последние годы все чаще рассматриваемые системы используются для управления человеком. Как отмечается в одной из статей, посвященной использованию информационных технологий в системе управления персоналом, «на сегодняшний день использование информационных технологий в управлении персоналом - это необходимое условие для того, чтобы обеспечить эффективную работу любой компании» [8].

Получается, что человек добровольно передает часть своих функций управления другими людьми автоматизированным системам. Следовательно, логичным является 
вопрос, кто в такой ситуации должен нести ответственность за допущенные нарушения в результате сбоя автоматизированной системы управления. На основе имеющегося опыта взаимодействия человека и техники ответственность несет человек. Вместе с тем в результате развития инновационной деятельности, как отмечалось ранее, системы взаимоотношений человека и техники меняются, в результате чего так однозначно ответить на обозначенный вопрос в будущем будет все сложнее. В этой связи законодателю следует более внимательно относиться к использованию такого средства законодательной техники, как терминология уголовного закона, и обдуманно включать в его текст новые дефиниции.

Другой аспект рассматриваемой проблемы заключается в том, что общественные отношения под воздействием инновационной деятельности претерпевают определенные изменения. В этой связи трансформируется и объект преступления. Так, например, такой традиционный объект преступления, как собственность, известный законодателю с первых законодательных источников уловного права, наделяется новыми свойствами. С формированием общества, в котором основными производственными ресурсами выступают информация и знания, а средства их создания и передачи становятся доступными множеству отдельных людей, возникает ситуация, когда, с одной стороны, каждый желающий может приобрести современные информационные средства в личное владение, а с другой - люди, которые не могут эффективно присваивать сложные информационные продукты, не могут ими обладать в полной мере [9]. В результате появляется новый вид собственности, а именно интеллектуальная собственность, которая также подлежит уголовно-правовой охране. Вместе с тем, по нашему мнению, оперирование со стороны ученых и практиков таким понятием, как интеллектуальная собственность, вызывает противоречия. Так, по своей сути интеллектуальную собственность к собственности отнести нельзя, это частично подтверждает и законодатель, располагая значительное число норм, посягающих на рассматриваемую группу отношений, за пределами главы «Преступления против собственности». Кроме того, как верно отмечает Н. А. Лопашенко, «к имуществу не относятся и, значит, предметом посягательств на собственность не являются интеллектуальная собственность и нематериальные блага. Последние не несут в себе экономического содержания собственности, а следовательно, лишены и ее юридического содержания» [5, с. 34-35]. Отмеченное также является проблемой, которую придется впоследствии решать.

Таким образом, сегодня назрела необходимость объединения норм в области преступлений, посягающих на инновационную деятельность, в отдельную группу. Указанные общественные отношения обладают рядом особенностей, позволяющих рассмотреть вопрос о формировании их в отдельный видовой объект преступления. Выделение групп преступлений в области инновационной деятельности будет иметь серьезное значение. В частности, это позволит устанавливать общественную опасность применительно к группе преступлений, а также анализировать изменения степени общественной опасности преступления в зависимости от видов квалифицирующих и привилегирующих обстоятельств. Кроме того, проведенное деление будет способствовать повышению эффективности дифференциации ответственности, системности уголовного закона, а также позволит облегчить процесс квалификации уголовно наказуемого деяния.

\section{СПИСОК ЛИТЕРАТУРЫ}

1. Автоматизированная система управления. URL: http://o-ili-v.ru/wiki/ (дата обращения: 22.12.2018).

2. Власова, Е. М. Изменение отношения человек - техника в современном обществе: проблема нового гуманизма / Е. М. Власова // Международный журнал прикладных и фундаментальных исследований. - 2015. - № 1. - С. $170-173$

3. Дуров, А. А. Механизация человека и гуманизация машины: тенденции существования человека и техники / А. А. Дуров, В. А. Починская, А. Р. Шарипова // Социум и власть. - 2018. - № 3 (71). - С. 7-14.

4. Жукова, E. А. Hi-Tech: динамика взаимодействий науки, общества и технологий : автореферат диссертации на соискание ученой степени доктора философских наук. - Томск, 2007. - 37 с.

5. Лопашенко, Н. А. Посягательства на собственность : монография / Н. А. Лопашенко. - Москва : Норма, Инфра-М, 2012. - 528 с. - ISBN 978-5-4396-1743-2.

6. Мухамедзянова, Д. Роботы должны нести уголовную ответственность / Д. Myхамедзянова. URL: https:// hightech.fm/2017/04/04/intelligence-systems (дата обращения: 05.11.2018).

7. Ожегов, С. И. Толковый словарь русского языка / С. И. Ожегов, Н. Ю. Шведова. - Москва : Азбуковник, 1999. 944 c. - ISBN 5-89285-003-X.

8. Полещук, Ж. А. Использование информационных технологий в системе управления персоналом / Ж. А. Полещук, И. В. Галетта // Проблемы современной науки и образования. - 2017. - № 23. - С. 28-31.

9. Поломошнов, А. Ф. Философия и современный мир : курс лекций / А. Ф. Поломошнов, И. М. Лаврухина, П. А. Поломошнов. - Персиановский : Донской ГАУ, 2015. - С. 55-58. 
10. ФРГ глазами западногерманских социологов : Техника - интеллектуалы - культура / [К. Г. Барбакова, Л. И. Войтенко, Л. Д. Гудков и др.] ; ответственный редактор Ю. Н. Давыдов. - Москва : Наука, 1989. - 342 с.- ISBN 5-02013344-2.

\section{REFERENCES}

1. Avtomatizirovannaya sistema upravleniya [Automated control system]. Available at: URL: http://o-ili-v.ru/wiki/ (accessed 22.12.2018). (In Russ.).

2. Vlasova E. M. Izmenenie otnosheniya chelovek - tekhnika v sovremennom obshchestve: problema novogo gumanizma [Changing the relationship of man - technology in modern society: the problem of a new humanism]. Mezhdunarodnyj zhurnal prikladnyh i fundamental'nyh issledovanij - International journal of applied and fundamental research, 2015, no. 1, pp. 170-173. (In Russ.).

3. Durov A. A., Pochinskaya V. A., SHaripova A. R. Mekhanizaciya cheloveka i gumanizaciya mashiny: tendencii sushchestvovaniya cheloveka i tekhniki [Human mechanization and humanization of a machine: trends in human existence and technology]. Socium i vlast' - Society and power, 2018, no. 3 (71), pp. 7-14. (In Russ.).

4. ZHukova E. A. Hi-Tech: dinamika vzaimodejstvij nauki, obshchestva i tekhnologij. Avtoref. diss. dokt. filos. nauk [Hi-Tech: the dynamics of the interactions of science, society and technology. Author's abstract of the diss. Dsc. in Philosophy]. Tomsk, 2007. 37 p. (In Russ.).

5. Lopashenko N. A. Posyagatel'stva na sobstvennost' [Property infringement]. Moscow, 2012. 528 p. (In Russ.).

6. Muhamedzyanova D. Roboty dolzhny nesti ugolovnuyu otvetstvennost' [Robots must be held criminally liable]. Available at: URL: https://hightech.fm/2017/04/04/intelligence-systems (accessed 05.11.2018). (In Russ.).

7. Ozhegov S. I., SHvedova N. YU. Tolkovyj slovar' russkogo yazyka [Explanatory dictionary of the Russian language]. Moscow, 1999. 944 p. (In Russ.).

8. Poleshchuk ZH. A., Galetta I. V. Ispol'zovanie informacionnyh tekhnologij v sisteme upravleniya personalom [The use of information technology in the personnel management system]. Problemy sovremennoj nauki i obrazovaniya - Problems of modern science and education, 2017, no. 23, pp. 28-31. (In Russ.).

9. Polomoshnov A. F., Lavruhina I. M., Polomoshnov P. A. Filosofiya i sovremennyj mir [Philosophy and the modern world]. Persianovsky, 2015. 224 p. (In Russ.).

10. Davydov YU. N. (red.) FRG glazami zapadnogermanskih sociologov [Germany through the eyes of West German sociologists]. Moscow, 1989. 342 p. (In Russ.). 